\title{
REDES DE PROMOÇÃO INTERNACIONAL E SUAS CONTRIBUIÇÕES NO PROCESSO DE INTERNACIONALIZAÇÃO: O CASO DO PSI WINES FROM \\ BRAZIL
}

\author{
Marlon Dalmoro \\ mdalmoro@ea.ufrgs.br
}

Universidade Federal do Rio Grande do Sul - Porto Alegre, RS / Brasil

\begin{abstract}
Recebido em 25/02/2010
Aprovado em 30/08/2011

Disponibilizado em 01/08/2012

Avaliado pelo sistema double blind review

Revista Eletrônica de Administração

Editor: Luís Felipe Nascimento

ISSN 1413-2311 (versão on-line)

Editada pela Escola de Administração da Universidade Federal do Rio Grande do Sul. Periodicidade: Quadrimestral
\end{abstract}

Sistema requerido: Adobe Acrobat Reader.

\section{RESUMO}

O presente estudo foca a natureza de redes de promoção internacional formais, formadas por empresas que operam no mesmo setor e país de origem. O objetivo é analisar uma rede de promoção internacional e a sua contribuição no processo de internacionalização das empresas afiliadas. Para tanto, foi realizada uma revisão na literatura sobre os temas de redes interorganizacionais de cooperação, internacionalização e a formação de redes para internacionalização, bem como a coleta de evidências empíricas por meio de uma abordagem qualitativa utilizando-se do método de estudo de caso. A unidade de análise consiste no Projeto Setorial Integrado (PSI) Wines From Brazil, formado por 39 empresas do setor vinícola e mantido pelo Instituto Brasileiro do Vinho - IBRAVIN com o apoio da APEX Brasil e observada por meio da visão de issue-based net, com foco nas interligações entre os membros da rede. A coleta das evidências ocorreu durante visitas in loco, por meio de entrevistas semiestruturadas com os gestores de 14 empresas participantes da rede, mais dois gestores executivos do projeto Wines From Brazil. Os dados foram interpretados por meio da técnica de análise de conteúdo. Como auxílio à análise, foi elaborada uma matriz de agrupamento conceitual, formada por quatro construtos: relação entre os atores, políticas governamentais, efeitos da participação na rede e geração de mudanças. Os resultados indicam que a formação da rede contribui no processo de internacionalização das empresas associadas principalmente por meio do suporte financeiro e da troca de informações e conhecimentos. A rede consiste numa estrutura de ligação entre empresas, governo e entidades setoriais que permite a troca de recursos necessários para a internacionalização. A associação em redes consiste numa opção estratégica, especialmente no caso de setores menos desenvolvidos internacionalmente. Em adição, os resultados apontam para os efeitos das políticas setoriais de estímulo à formação de redes de promoção internacional.

Palavras-chave: Processo de Internacionalização, Redes, Promoção Internacional, Vinhos, Wines from Brazil. 


\title{
INTERNATIONAL PROMOTION NETWORKS AND THEIR CONTRIBUTION IN THE INTERNATIONALIZATION PROCESS: PSI WINES FROM BRAZIL
}

\author{
CASE
}

\begin{abstract}
This study focuses the formal international promotion networks, formed by companies that operate in the same sector and country of origin. The objective is to analyze an international promotion network and its contribution in the internationalization process of affiliates companies. For this, it was carried out a literature review on the following topics: network cooperation, internationalization and network formation for internationalization. Empirical evidence was collected through a qualitative approach through a case study. The unit of analysis was the Integrated Sector Project (PSI) Wines from Brazil, formed by 39 wine companies and supported by the Brazilian Institute of Wine - IBRAVIN and APEX Brazil. Network was observed through issue-based net view, focusing on the linkages between network members. Empirical evidence was collected during visits in loco, through semi-structured interviews with 14 companies' managers and two network managers. Data were interpreted using the content analysis technique. For analysis support, it was developed a conceptual matrix, with four constructs: relationships between stakeholders, government policies, network participation effects and changes generation. Results indicate that the network formation contributes with internationalization process of affiliates companies mainly through financial support and information and knowledge exchange. Network consists in a structural link between companies, government and sectorial institutions that enables the exchange of resources required for internationalization. Networks affiliation is a strategic option, especially for less internationally developed industries. Furthermore, results point out effects of sectorial policy that stimulate the formation of international promotion networks.
\end{abstract}

Keywords: Internationalization Process, Networks, International Promotion, Wines, Wines from Brazil.

\section{INTRODUÇÃO}

Alterações do ambiente competitivo promovido pela abertura das economias e acordos de natureza econômico-comercial entre países intensificaram a concorrência entre as empresas (CHESNAIS, 1996). Focando o setor vinícola especificamente, com a entrada de novos países produtores no mercado global, a oferta vinícola tornou-se mais acirrada internacionalmente (GARCIA-PARPET, 2004). Os países do chamado Novo Mundo vinícola estruturaram-se de forma diferenciada, adotando normas de qualidade e classificação, produção em larga escala, integração na cadeia produtiva, gerando uma competição acirrada no setor vinícola mundial.

Neste contexto, empresas do setor vinícola de todo o mundo têm usado diversos arranjos organizacionais para aprimorar o desempenho do seu negócio, especialmente com a utilização de arranjos colaborativos, nos quais a eficiência individual é 
Redes de promoção internacional e suas contribuições no processo de internacionalização: o caso do psi wines from brazil

transformada em eficiência coletiva (RING; VAN DE VEN, 1992; FLEURY; FLEURY, 2003). Colaboração por meio de redes interorganizacionais tem sido utilizada pelos setores vinícolas de diversos países (ex. Nova Zelândia, Austrália, Argentina e Chile) para auxiliar as operações internacionais das empresas associadas. Assim, por meio da união de empresas do mesmo setor, estas redes visam à promoção de exportações através da criação de diferentes tipos de contatos e relações entre empresas que resultam no desenvolvimento de conhecimento e atividades conjuntas (WELCH; WELCH; YOUNG; WILKINSON, 1998; BELSO-MARTINEZ, 2006).

Mesmo apresentando uma evolução recente, o setor vitivinícola brasileiro encontra-se num grau de desenvolvimento inferior em relação aos principais competidores internacionais. A cooperação das empresas vinícolas brasileiras por meio de redes interorganizacionais passa a ser uma saída para reduzir as barreiras e competir com grandes estruturas organizacionais. No caso brasileiro, foi desenvolvida a rede denominada Wines from Brazil. Esta rede é gerenciada pelo Instituto Brasileiro do Vinho - IBRAVIN com apoio da Agência Brasileira de Promoção de Exportações APEX Brasil e outros parceiros institucionais.

A literatura existente sugere que a teoria de redes é útil para a compreensão do processo de internacionalização (SADLER; CHETTY 2000; COVIELLO; MUNRO, 1995). Os efeitos das redes no processo de internacionalização têm sido examinados em vários estudos desde a década de 1980, quando Johanson e Mattsson (1988) apresentaram essa discussão no campo das redes industriais.

No entanto, poucos estudos descrevem o fenômeno empírico de formação de redes para a internacionalização no âmbito de redes formais horizontais. Além disso, olhar para o contexto local torna-se um elemento fundamental no entendimento do processo de internacionalização, uma vez que as especificidades do país, como políticas públicas, desenvolvimento do setor e estágio de internacionalização podem afetar a formação e o funcionamento das redes industriais (JOHANSON; MATTSSON, 1988; SAKAKIBARA; DODGSON, 2003; PARKHE; WASSERMAN; RALSTON, 2006).

Este artigo foca a natureza de redes de promoção internacional formais, formadas por empresas que operam no mesmo setor e país de origem e tem como objetivo analisar uma rede de promoção internacional e a sua contribuição no processo de internacionalização das empresas afiliadas. Para isto, um estudo de caso foi realizado no Projeto Setorial Integrado Wines from Brazil.

O trabalho foi dividido em cinco partes, incluindo a introdução já apresentada. A seguir, é apresentada uma revisão da literatura sobre os temas de redes 
interorganizacionais de cooperação, internacionalização e a formação de redes para internacionalização. Após, apresenta-se o método utilizado para a realização da pesquisa, seguido dos resultados do estudo de caso e das considerações finais.

\section{O PROCESSO DE INTERNACIONALIZAÇÃO EM REDES}

\subsection{Redes Interorganizacionais de Cooperação}

Na concepção de Dyer e Singh (1998) intensifica-se a reorganização dos modos de gestão empresarial com a finalidade de compatibilizar a organização com padrões mais avançados de qualidade e produtividade, criando estratégias colaborativas como forma de adquirirem habilidades que ainda não possuem. Castells (1999) conceitua redes como um conjunto de elos interconectados. Por sua amplitude, esse conceito é utilizado em diversas áreas do conhecimento.

No âmbito empresarial, as redes consistem numa estrutura formada por um agrupamento de empresas, com o objetivo de favorecer a atividade de cada uma das empresas, sem que estas tenham que unificar os laços financeiros entre si. As associações em redes são uma forma específica de estrutura organizacional que as empresas podem utilizar para implementar suas estratégias (BARNEY, 1991).

Na concepção de Marcon e Moinet (2000), para que uma rede ocorra na prática, deve ocorrer a combinação de três elementos principais: a) recursos a trocar, como informação, conhecimento e insumos, visto que se o conjunto de atores que formam a rede não possuem nada a trocar, dificilmente constituirão a rede; b) estrutura que designa um conjunto de regras de funcionamento e a observação da ética pelos membros; e, c) infraestrutura para colocar em prática as ações, como orçamento, local, material, comunicação, conexão eletrônica, entre outros meios que permitam a operacionalização das atividades da rede. A partir da existência destes elementos, a rede terá condições de cumprir com o seu papel e gerar vantagens para as empresas.

Nesta linha, Ebers e Jarrilo (1997) destacam como vantagens competitivas propiciadas pela ação em rede: o aprendizado mútuo entre as empresas, a estratégia de coespecialização, o melhor fluxo e coordenação das informações entre as empresas, as economias de escala, o compartilhamento de riscos e a superação de barreiras de entrada. Já Miles e Snow (1986) afirmam que a redução de custos e riscos em termos de produção, transação e informação consistem no principal elemento motivador da 
Redes de promoção internacional e suas contribuições no processo de internacionalização: o caso do psi wines from brazil

cooperação em rede, especialmente quando existe uma complementaridade por parte das empresas.

Além disso, as redes de cooperação permitem acesso às novas tecnologias e informações de mercado, fruto de um arranjo organizacional cooperativo (POWELL, 1987). Contudo, a cooperação dentro da rede envolve alta carga emocional dos participantes, exigindo a existência de confiança mútua entra as empresas cooperadas (GRANOVETTER, 1973). A confiança aparece como um fenômeno intrinsecamente ligado à rede, envolvendo não só as empresas, mas também os diversos atores envolvidos nela, como entidades governamentais e setoriais (ASSENS; BOUCHIKHI, 1999). No caso de redes que visam atividades internacionais, a confiança tem um papel importante, pois, ao mesmo tempo em que as empresas cooperam nas atividades internacionais, elas competem no mercado interno (ASSENS; BOUCHIKHI, 1999).

No que tange às diferentes configurações de redes interorganizacionais, estas podem ser classificadas de acordo com seu grau de formalidade (CHETTY; AGNDAL, 2008). Focando especificamente as redes interorganizacionais formais, estas permitem somente a entrada de organizações que estão alinhadas e comprometidas com os objetivos da rede. Neergaard (1999) ressalta um tipo específico de redes: as redes formadas por estímulo governamental. Em diversos países, existem redes suportadas por auxílio governamental, que podem incluir diversos objetivos como a promoção de exportações, por exemplo.

Em termos de topologia da rede, a definição do tipo de rede analisada neste trabalho é: as redes são intencionalmente formadas por grupos de pequenas e médias empresas, que estão geograficamente próximas e competem no mercado interno, operam no mesmo setor e realizam interações diretas entre elas, objetivando a internacionalização, com a participação de entidades públicas (governamentais ou não) que visam a promoção de exportação.

\subsection{Processo de Internacionalização de Empresas}

O processo de internacionalização é descrito por Lam e White (1999) como o processo pelo qual as organizações aumentam sua consciência sobre a importância na participação em atividades internacionais, envolvendo-se em diversas operações além de suas fronteiras.

A internacionalização de uma empresa pode ser entendida como um processo. Esta visão vem sendo desenvolvida a partir do trabalho seminal de Penrose (1959) e a

REAd I Porto Alegre - Edição 72 - N 2 - maio/agosto 2012 - p. 552-580 
obra de Cyert e March (1963) e desde então tem sido analisada com diversos enfoques. De um lado, encontram-se os estudos de abordagem comportamental, baseados na escola nórdica - Modelo de Uppsala, os quais apresentam a internacionalização como consequência de uma sequência de estágios relacionados com a experiência e o conhecimento dos mercados externos (JOHANSON; WIEDERSHEIM- PAUL, 1975; JOHANSON; VAHLNE, 1977). De acordo com o modelo, o conhecimento empírico reduz a percepção de risco e as incertezas das operações internacionais, pois possibilita uma aprendizagem inconsciente, que leva a passos incrementais no processo de internacionalização (JOHANSON; VAHLNE, 1977). Cavusgil (1985) também destaca a importância da aquisição de informação e aprendizagem como um elemento chave na atividade exportadora.

De outro lado, estão os trabalhos que se apoiam em uma abordagem econômica, proporcionada pela teoria dos Custos de Transação (WILLIAMSON, 1975), a partir da teoria de internalização (BUCKLEY, 1988) e do paradigma eclético da produção (DUNNIG, 1988), na qual as empresas organizam suas atividades pelo mercado ou por hierarquia, na envolvente de aspectos do ambiente (incertezas e complexidade) e o comportamento humano (racionalidade limitada e oportunismo).

Em outro momento, a questão dos laços interorganizacionais passou a ser destacada como um dos elementos centrais no processo de internacionalização. Com base nesse aspecto, desenvolveu-se a teoria de redes (JOHANSON; MATTSSON, 1988). Nessa perspectiva teórica, o processo de internacionalização seria tanto 'inter' quanto intraorganizacional (JOHANSON; MATTSSON, 1988; JOHANSON; VAHLNE, 2009).

A teoria de redes destaca que as decisões orgânicas com orientação externa partem de um princípio que considera a influência de agentes externos, mais especificamente dos relacionamentos entre as empresas no processo de internacionalização (JOHANSON; MATTSSON, 1988). Faz parte deste grupo o estudo da internacionalização através de redes como estrutura de governança. Como destaca Pedersen (2002, p.3), "nesta perspectiva, a internacionalização acontece numa relação diádica entre parceiros que possuam recursos complementares. É o acesso a recursos escassos que determina o caminho seguido no processo de internacionalização".

Com base na teoria de redes, Chetty e Wilson (2003) argumentam que as redes de negócios permitem o acesso a diversos recursos necessários à estratégia de internacionalização da firma. Assim, para os autores, os recursos proporcionados pela rede podem ser uma importante variável para explicar o engajamento internacional. 


\subsection{Internacionalização em Redes Interorganizacionais}

No início da década de 1980, mais precisamente em 1982, o International Marketing and Purchasing Group (IMP Group), desenvolveu os primeiros esforços para a análise do papel das relações de longo prazo nos negócios, através do "Modelo de Interação" (WILSON; WOODSIDE, 1985). Neste modelo, as interações se dariam com clientes, clientes dos clientes, distribuidores, fornecedores, fornecedores suplementares, consultores, órgãos governamentais, associações empresariais, entre outros. Os laços se dariam não somente pelas atividades empresariais, mas também em termos pessoais, sendo estes fundamentais, principalmente no início do processo de internacionalização.

Com base nesta perspectiva, os mercados industriais podem ser vistos como redes de relacionamentos entre empresas. Para Johanson e Mattsson (1988), a rede de negócio surge por meio das relações que a empresa tem com seus consumidores, distribuidores, fornecedores, competidores e governo. Eles complementam ainda que, embora estas relações sejam comuns em qualquer negócio, nas empresas internacionalizadas, o número e a força das relações entre os atores da rede aumentam.

No modelo de Johanson e Mattsson (1988), os ativos de mercado que a empresa possui são distintos se a empresa está internacionalizada ou não. Estes ativos também estão relacionados ao grau de internacionalização em que o mercado se encontra. Desta forma, para os autores, o desenvolvimento do processo de internacionalização é influenciado não só pelo grau de internacionalização da empresa, mas também pelo grau de desenvolvimento internacional do mercado em que ela opera.

Em complemento, Johanson e Mattsson (1988) ressalta que o processo de internacionalização em rede necessita de um desenvolvimento gradual de conhecimento de mercados e de aprendizado com as outras empresas da rede. Nesta linha, Elo (2005) apresenta três pré-requisitos necessários para a aparição de uma rede internacional: problema comum ou oportunidade; as empresas preferem atuar conjuntamente; e o conteúdo da cooperação ser importante para o rendimento da empresa.

Alinhados com a perspectiva de relacionamentos em redes no processo de internacionalização, Hakansson e Johanson (1992) propuseram um modelo de redes industriais chamado de Modelo Atores-Recursos-Atividades (ARA). Este modelo configura-se pela articulação entre os atores, as atividades desenvolvidas por estes e os recursos disponibilizados na rede. A interligação destes três elementos representa a base para o estabelecimento de redes industriais. O relacionamento dentro da rede é 
estimulado quando existe uma heterogeneidade na oferta de recursos entre os atores, facilitando a criação, utilização e transferência de conhecimento, inovações e knowhow, essenciais no processo de internacionalização (HAKANSSON; JOHANSON, 1992).

Assim, o desenvolvimento de estratégias interorganizacionais pode constituir-se em um importante mecanismo no processo de internacionalização, pois permite que as empresas compartilhem recursos para entrar em mercados externos (ELANGO; PATTNAIK, 2007; CHETTY; AGNDAL, 2008). Neste processo, as entidades governamentais ou setoriais, como as agências de apoio à exportação, são atores chaves no estímulo à internacionalização (CHEN; CHEN, 1998; LOANE; BELL, 2006).

De acordo com Welch et al. (1998), muitos países têm utilizado uma variedade de esquemas de promoção de exportações em uma tentativa de melhorar o desempenho das exportações. No entanto, observa-se que os formuladores de políticas públicas ainda estão à procura de uma forma mais eficaz de intervir para promover e apoiar a exportação. Neste sentido, a formulação de redes de exportação, ao passo que proporciona recursos necessários para a internacionalização, também possui limitações (WILKINSON; MATTSSON; EASTON, 2000).

Entre os efeitos positivos do relacionamento em redes, destacam-se as reduções de custos, crescimento de flexibilidade, acesso a recursos, conhecimento de mercados, redução do custo de transação, entre outros. Estes efeitos tornam as empresas mais competitivas, possibilitando o desenvolvimento de atividades em mercados externos com mais sucesso (SEPPO, 2007, ROOLAHT, 2006).

Chetty e Holm (2000) destacam que a associação em redes permite às empresas aprender com as experiências de outras empresas, obter novos conhecimentos, se expor a novas oportunidades - dado o efeito sinérgico proporcionado pelo conjunto de recursos existente na rede. Brito (2007) apresenta os benefícios da cooperação em rede no processo de internacionalização por meio das vantagens operacionais e estratégicas. Como vantagens operacionais o autor destaca que as redes propiciam alcance a melhores meios de financiamento e a partilha das despesas de investimentos pelas empresas associadas; redução de custos por meio de economia de escalas; sinergias e economias de experiência; novos métodos de gestão pela partilha de know-how e redução do risco. No âmbito estratégico, o autor destaca os benefícios por meio de reforço das vantagens competitivas e atuação sobre o nível de concorrência do setor.

$\mathrm{Na}$ tangente dos efeitos negativos, Echeverri-Carrol, Hunnicutt e Hansen (1998) e Seppo (2007) destacam as assimetrias na rede, como diferenças entre o tamanho das 
Redes de promoção internacional e suas contribuições no processo de internacionalização: o caso do psi wines from brazil

empresas, visto que as empresas com poder maior dentro da rede podem deter o controle do conhecimento e das informações estratégicas. Já Coviello e Munro (1995) levantam a questão das assimetrias na rede, destacando que estas diferenças não são frutos somente do tamanho da empresa, mas também, de questões como diferentes níveis de conhecimentos sobre o mercado.

O reconhecimento da limitação das redes no processo de internacionalização não deve ser tomado como um argumento que leva à minimização do papel da rede. Para esta pesquisa, a rede é considerada como ligações de negócios entre as empresas que vêm do mesmo país e setor, afiliadas a uma rede formal, visando desenvolver ações internacionais. Parte-se do pressuposto teórico de que a formação de redes de exportação representa um passo importante para a internacionalização, especialmente onde há um predomínio de pequenas e médias empresas. A relação entre os atores e as políticas governamentais forma um ambiente propício à internacionalização, resultando em efeitos positivos no processo de internacionalização e mudanças internas nas empresas afiliadas à rede.

\section{PROCEDIMENTOS METODOLÓGICOS}

O presente estudo possui um corte transversal por meio de uma abordagem qualitativa, visto que busca analisar descritivamente o processo de internacionalização de empresas por meio de uma rede interorganizacional horizontal. A pesquisa qualitativa permite a identificação de forças causais que influenciam o comportamento dos atores e a criação da rede, tornando-se apropriada para pesquisa em redes industriais (EASTON, 1992). Ao nível da análise, utiliza-se da estratégia de pesquisa de estudo de caso. Para Elo (2005) o método de estudo de caso caracteriza-se como uma ferramenta importante para estudos contemporâneos em redes de negócios.

$\mathrm{Na}$ realização de estudos em redes de empresas, Brito (1999) destaca a dificuldade de definição dos sujeitos da pesquisa, visto a dicotomia nas duas opções previsíveis: o uso de uma organização focal como unidade de amostra versus a adoção de rede global como unidade de análise. Para superar este desafio, o autor apresenta uma opção intermediária, nomeada de issue-based net. Esta opção consiste na forma de associação baseada na relação entre os atores que objetivam cooperar com uma questão coletiva, influenciando a estrutura e a evolução do sistema ao qual eles pertencem, através de um controle de atividades, recursos e outros atores. O uso de issue-based net para capturar a unidade de análise pode ser considerado uma solução prática para 
capturar o caráter de conexão na rede, fornecendo uma perspectiva holística desta (BRITO, 1999). Dessa forma, no presente estudo, a unidade de análise será vista por meio da visão de issue-based net, com foco nas interligações entre os membros da rede.

A unidade de análise consiste no Projeto Setorial Integrado (PSI) Wines From Brazil, formado por 39 empresas do setor vinícola e mantido pelo Instituto Brasileiro do Vinho - IBRAVIN com o apoio da Agência Brasileira de Promoção de Exportações e Investimentos - APEX Brasil, cujos sujeitos da pesquisa foram os atores formadores desta rede.

A partir da base teórica, foram coletadas evidências empíricas na rede escolhida. Esta coleta seguiu as orientações de Yin (2001) e Yeung (1995) e utilizou como fontes de evidências entrevistas e análise de documentos. A coleta destas evidências deu-se durante visitas in loco, realizadas pelo pesquisador nos meses de setembro e outubro de 2008.

A análise de documentos foi conduzida a partir de artefatos coletados durante a condução da pesquisa, incluindo folders e materiais promocionais da rede e das empresas participantes, publicações, notícias e documentos contidos no website da rede. Estes documentos foram utilizados principalmente na descrição do caso, além de proporcionar um melhor entendimento das evidências obtidas nas entrevistas.

Para a coleta de dados primários, foram realizadas entrevistas semiestruturadas com os gestores de 14 empresas participantes da rede, mais dois gestores executivos do projeto Wines From Brazil, totalizando 16 entrevistas. Para guiar a entrevista, foi elaborado um roteiro com 15 questões abertas. Por não prever todas as situações e condições de trabalho de campo, algumas questões foram introduzidas no momento das entrevistas.

Para as entrevistas, buscou-se empresas que possuíssem características heterogêneas dentro da rede, englobando empresas que já desenvolviam atividades exportadoras anteriormente à rede, outras que se internacionalizaram a partir da entrada da rede e outras que ainda não realizaram nenhum embarque para o exterior. Os entrevistados foram selecionados pelo envolvimento nas atividades internacionais da empresa e participação nas ações do Wines from Brazil. Na definição do número de entrevistas, utilizou-se o princípio de saturação proposto por Glaser e Strauss (1967). A Tabela 01 apresenta o perfil dos sujeitos participantes da pesquisa.

Tabela 01 - Lista dos Sujeitos da Pesquisa

\begin{tabular}{l|l|l} 
Empresa & Entrevistado & Cidade \\
\hline
\end{tabular}


Redes de promoção internacional e suas contribuições no processo de internacionalização: o caso do psi wines from brazil

\begin{tabular}{l|l|l}
\hline Rede Wines From Brazil & Gerente do Projeto & Bento Gonçalves - RS \\
\hline Rede Wines From Brazil & Gerente do IBRAVIN & Bento Gonçalves - RS \\
\hline Vallontano Vinhos Nobres & Diretora & Bento Gonçalves - RS \\
\hline União de Vinhos & Diretora & Flores da Cunha - RS \\
\hline Sulvin Ind. E Com. Vinhos & Enólogo & Flores da Cunha - RS \\
\hline Luiz Argenta Vinhos Finos & Gerente Comercial & Flores da Cunha - RS \\
\hline Soc. de Bebidas Mioranza & Gerente Comercial & Flores da Cunha - RS \\
\hline Vinícola Garibaldi & Gerente de Marketing & Garibaldi - RS \\
\hline Vinícola Don Laurindo & Diretor & Bento Gonçalves - RS \\
\hline Vinícola Miolo & Gerente de Exportação & Bento Gonçalves - RS \\
\hline Casa Valduga Vinhos Finos & Gerente de Exportação & Bento Gonçalves - RS \\
\hline Vinhos Don Candido & Gerente de Marketing & Bento Gonçalves - RS \\
\hline Coop. Vinícola Aurora & Gerente de Exportação & Bento Gonçalves - RS \\
\hline Dal Pizzol Vinhos Finos & Enóloga & Bento Gonçalves - RS \\
\hline Lidio Carraro Vinicola & Diretora & Bento Gonçalves - RS \\
\hline Soc. De Bebidas Panizzon & Gerente de Exportação & Flores da Cunha - RS \\
\hline
\end{tabular}

Fonte: Elaborado pelo autor do trabalho

Para realizar a análise das evidências empíricas, optou-se pela análise de conteúdo, sugerida por Bardin (1977). Para a autora, esta técnica visa, por meio de procedimentos sistemáticos e objetivos de descrição do conteúdo, a geração de indicadores que permitam a inferência de conhecimentos. Análise de conteúdo é a técnica de análise de dados que pretende fazer a conexão entre a teoria prévia levantada na revisão de literatura e o que na prática foi encontrado na coleta de dados (PERRY, 1998).

Como auxílio à análise, foi elaborada uma matriz de agrupamento conceitual. Com essa matriz, as entrevistas foram organizadas em categorias que possuem correspondência com a fundamentação teórica deste trabalho e que correspondem aos objetivos do estudo (Tabela 02).

Tabela 02 - Matriz de Agrupamento Conceitual

\begin{tabular}{|c|c|c|c|}
\hline Objetivo & Construtos & Variáveis & Principais Autores \\
\hline $\begin{array}{l}\text { Papel da rede e } \\
\text { contribuições no } \\
\text { processo de } \\
\text { internacionalização }\end{array}$ & $\begin{array}{c}\text { Relação entre os } \\
\text { atores }\end{array}$ & $\begin{array}{c}\text { - Teoria dos custos de transação, } \\
\text { - Grau de internacionalziação do } \\
\text { mercado e das empresas; } \\
\text { - Grau de conexão entre os } \\
\text { parceiros; } \\
\text { - Teoria de redes }\end{array}$ & $\begin{array}{c}\text { Wiliamson (1975); } \\
\text { Johanson e Vahlne (1977) } \\
\text { Johanson e Mattsson } \\
\text { (1988); } \\
\text { Brito (2007); } \\
\text { Hakansson e Johanson }\end{array}$ \\
\hline
\end{tabular}




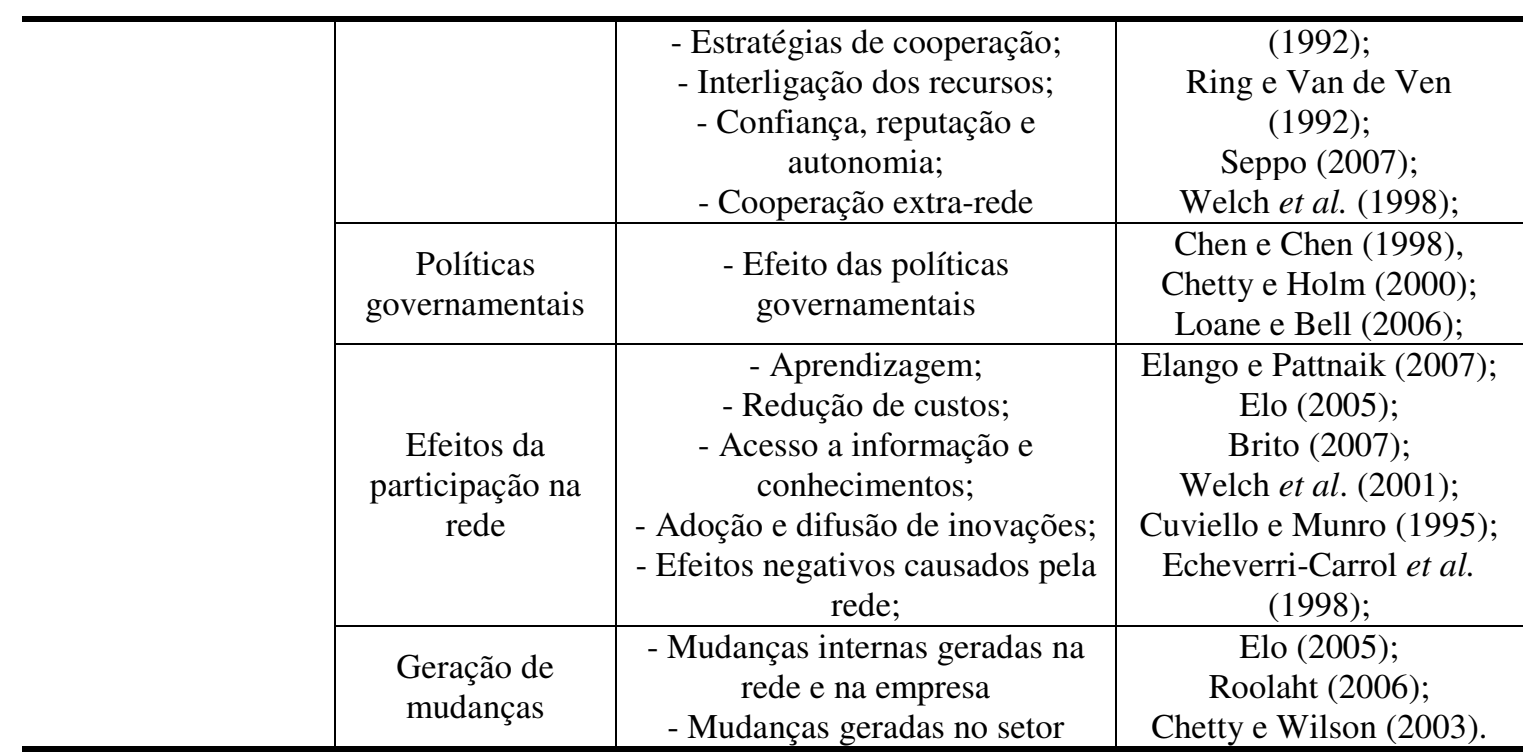

Fonte: Elaborado pelo autor do trabalho

\section{ANÁLISE DOS RESULTADOS}

$\mathrm{Na}$ última década, o mercado mundial vitivinícola passou por profundas transformações com o aumento da produção e entrada de novos países produtores, acompanhada de uma gradativa queda no consumo per capita. Inserido neste contexto, o setor vitivinícola brasileiro intensificou sua preocupação com a internacionalização no início dos anos 2000, com o expressivo aumento da concorrência com produtos importados. Segundo Fensterseifer (2007), no estágio atual da indústria de vinhos no Brasil e os agressivos esforços de exportação dos já estabelecidos países produtores de vinho, ingressar no mercado internacional pode ser um imperativo para a sobrevivência das vinícolas no seu próprio mercado doméstico.

A configuração do mercado mundial do vinho evidencia a necessidade de uma articulação dos atores e a construção de arranjos interorganizacionais para o processo de internacionalização das empresas do setor. A seguir, analisa-se o caso da Rede Wines From Brazil - sua formação, aspectos da gestão e a articulação dos atores para a constituição desta rede.

\subsection{A rede Wines from Brazil}

A rede interorganizacional Wines from Brazil teve início no ano de 2002, por iniciativa da Federação das Indústrias do Estado do Rio Grande do Sul e apoio da Agência de Brasileira de Promoção de Exportações, formada inicialmente por seis vinícolas gaúchas, com as características de um consórcio de exportação. Em 2004, esta 
Redes de promoção internacional e suas contribuições no processo de internacionalização: o caso do psi wines from brazil

iniciativa passou a ser um "Projeto Setorial Integrado" (PSI) focando a promoção de vinho brasileiro através de um acordo com o Instituto Brasileiro do Vinho - IBRAVIN.

O Wines From Brazil busca inserir o vinho brasileiro no mercado global. Nesse sentido, o desafio é a consolidação de uma imagem do país como produtor de vinho. As ações da rede estão centradas em quatro pilares, quais sejam: participação em feiras internacionais, realização de degustações, projeto comprador (que consiste em realizar atividades com importadores nas vinícolas), e projeto imagem (desenvolvido por ações junto à imprensa especializada).

As vinícolas participantes do projeto contam com auxílio financeiro para participação nas atividades de promoção comercial. O projeto também proporciona a troca de experiências entre as empresas participantes, além do fortalecimento da marca Wines From Brazil.

O processo de internacionalização no setor vinícola é uma alternativa para superar as dificuldades encontradas no mercado interno. As empresas estão vendo o mercado externo como uma alternativa estratégica em virtude do acirramento da concorrência de vinhos importados no mercado doméstico, da carga tributária, de acordos internacionais que não beneficiam as empresas locais e da incidência de contrabando.

A rede em análise é uma rede interorganizacional de vinícolas brasileiras, apoiada pelo governo e entidades representativas da indústria. O Wines From Brasil, enquanto rede de negócios pode ser caracterizada como um grupo intencionalmente formado de pequenas e médias empresas de um mesmo setor, visando à promoção internacional. O Wines From Brazil é aberto para todas as empresas brasileiras do setor que desejam utilizar a rede para buscar o mercado externo.

\subsection{Relação entre os atores}

O relacionamento em redes é fruto de três elementos: recursos a trocar, existência de uma estrutura coordenadora e uma infraestrutura que permita a troca de recursos (MARCON; MOINET, 2000). Na rede em estudo, observa-se a existência destes elementos de maneira consistente. As empresas participantes apresentam recursos a trocar, especialmente quanto a informações, elemento fundamental no processo de internacionalização. A rede está estruturada com um conjunto de regras e estatutos, bem como a existência de uma estrutura voltada para o cumprimento dos objetivos da rede. 
$\mathrm{Na}$ tangente da estrutura, destacam-se o apoio governamental proporcionado para aumentar a competitividade das vinícolas associadas à rede no mercado externo; a sede administrativa do projeto, que está localizada no mesmo espaço físico do IBRAVIN; e o website do projeto, que disponibiliza informações gerais e conteúdo on line exclusivo para os associados. No caso da rede em estudo, das 39 empresas associadas, 34 estão inseridas no arranjo produtivo vinícola da serra gaúcha, facilitando, assim, o contato pessoal entre os participantes.

O entendimento das relações entre os atores assume uma posição de destaque no processo de internacionalização (JOHANSSON; MATTSSON, 1988). Esse tipo de relação também é destaque na rede em estudo. A gerente da Luiz Argenta acredita que as vinícolas estão começando a ampliar seus horizontes, visualizando que no mundo, todos os fabricantes estão querendo atuar no mercado global. A entrevistada ainda destaca que a vinicultura brasileira cresceu devido à abertura que obteve, principalmente na busca de qualidade e tecnologia, objetivando, além de atingir o mercado externo, se desenvolver para poder competir com as empresas estrangeiras que estão entrando no mercado doméstico.

Pelo fato de o produto em análise ser o vinho, a gerente da Don Cândido ressalta que este produto exige processos diferenciados na sua internacionalização. Para a entrevistada, uma vinícola não consegue entrar em novos mercados sem a participação de outras integrantes da cadeia produtiva, visto a necessidade de uma adequação desde o plantio da uva até a disposição adequada do produto para os consumidores.

Nesta interligação de toda a cadeia, a gerente da Casa Valduga ressalta que os clientes têm contribuído para aumentar o volume de exportações por meio de indicação de novos importadores. Já o enólogo da Sulvin destaca o papel do governo como outro ator importante. Ele acredita que o apoio da APEX Brasil tem sido fundamental para a internacionalização da empresa.

A gerente da Casa Valduga acredita que, na medida em que aumenta o número de vinícolas exportadoras, o vinho brasileiro passa a ter mais exposição internacional e os importadores começam a buscar novas vinícolas, iniciando um movimento cíclico de crescimento internacional do setor como um todo. Este entendimento é exemplificado pelo gerente da Miolo, afirmando que geralmente o importador abre o espaço na gôndola por país, e com poucas variedades, não conseguiriam atender a gama de produtos necessária para preencher a gôndola. Desta forma, a rede contribuiu para proporcionar uma variedade maior de marcas e variedades para o importador. 
Redes de promoção internacional e suas contribuições no processo de internacionalização: o caso do psi wines from brazil

Outro elemento que compõe a relação entre os atores, destacado pelos entrevistados, é a união existente entre as empresas, como cita a gerente da Casa Valduga:

\footnotetext{
"Eu estou achando as vinícolas muito unidas, não tem aquela concorrência, até porque sabemos que os nossos concorrentes são os argentinos, mesmo no mercado interno. Nas feiras que a gente participa, cada um tem seu lugar, mas acaba representando um produto brasileiro e não a marca em si" [Gerente da Casa Valduga].
}

Neste sentido, a confiança mútua entre as empresas associadas na rede tem um papel fundamental para que ocorra a interação entre os participantes (GRANOVETTER, 1973). O gerente do IBRAVIN afirma que são desenvolvidas diversas atividades para estimular uma confiança mútua entre as empresas da rede e até mesmo com outras empresas do setor. Dentre estas atividades, ele destaca a divulgação do projeto, da responsabilidade que a administração da rede possui e estímulo às empresas para criarem uma filosofia de grupo.

$\mathrm{Na}$ visão da gerente da Casa Valduga, existe uma confiança mútua dentro da rede. Ela destaca o fato de que as empresas mais experientes no mercado internacional ajudam as empresas iniciantes em questões específicas, como na legislação, na documentação necessária. Para a gerente da Lídio Carraro, quando se está participando de uma feira, é o Brasil que está participando, não as empresas individualmente, e se o importador tiver alguma experiência mal sucedida com alguma empresa, ele vai estender esta imagem negativa para as demais empresas. Por outro lado, se uma empresa entrar em determinado mercado e realizar um bom trabalho, vai beneficiar as demais.

Uma rede deve proporcionar vantagens para todos os envolvidos, evitando assim o abandono e desengajamento em relação às ações da rede. Neste sentido, para a gerente da Casa Valduga, a configuração da rede proporciona vantagens para todos os associados constantemente, visto que, indiferente do volume de exportações, é atrativo para as empresas fazerem uso da rede, especialmente para participarem de feiras no exterior com o subsídio do projeto, mesmo que desenvolvam ações individuais extrarede.

A partir das colocações dos respondentes, adaptou-se o modelo de redes industriais (HACKANSSON; JOHANSON, 1992) de acordo com o contexto da rede em análise. No modelo, dentre os atores (aqueles que desempenham e controlam as

REAd I Porto Alegre - Edição 72 - № 2 - maio/agosto 2012 - p. 552-580 
atividades) destacam-se as empresas e as relações que estas mantêm; o IBRAVIN e a gerência do projeto como operacionalizadores das atividades, e a APEX Brasil, com o repasse de recursos financeiros. Estes recursos são os meios usados pelos atores para realizar as atividades. Estas atividades centram-se na promoção internacional de vinhos finos brasileiros. Para os entrevistados, são os recursos financeiros fornecidos pela rede para a promoção do vinho brasileiro que tornam a rede atrativa, em complemento com o auxílio técnico proporcionado pela gerência da rede e os recursos humanos das empresas, que colaboram mutuamente.

Por fim, adiciona-se ao modelo a variável da necessidade, ou seja, as relações geradas pelo tripé: atores, recursos e atividades ocorrem como fruto de uma necessidade por parte das empresas participantes da rede, de procurarem novos mercados para superar as dificuldades competitivas no mercado interno. A necessidade do relacionamento em rede para atuar no mercado externo supera a individualidade do setor, visto que o vinho brasileiro necessita desenvolver uma imagem no exterior, e, por intermédio da rede, é possível obter uma sinergia entre os atores, recursos e atividades. A Figura 01 expressa o modelo de redes industriais na rede em análise:

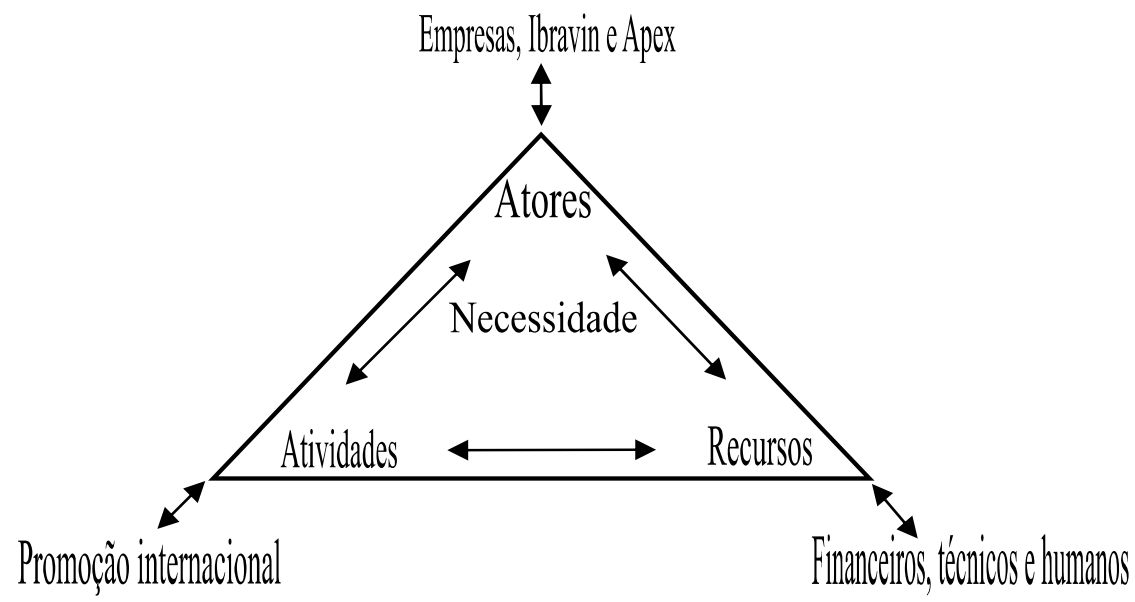

Figura 01 - Modelo de redes industriais na rede focal Fonte: Adaptado pelo autor a partir de Hakansson e Johanson (1992).

O formato das relações existentes na rede preserva a individualidade das empresas, visto que mesmo dentro da rede, cada empresa busca atingir seus objetivos individuais, até mesmo no momento da internacionalização. Cada empresa traça suas metas e mercados alvos individualmente e a rede serve como ferramenta para atingir este objetivo. Este formato favorece o contorno das individualidades de cada empresa sem prejudicar as relações na rede.

\subsection{Políticas governamentais}

REAd I Porto Alegre - Edição 72 - N 2 - maio/agosto 2012 - p. 552-580 
Estudos anteriores em redes de promoção internacional (CHEN; CHEN, 1998; NEERGAARD, 1999; LOANE; BELL, 2006) destacam o papel do governo como um catalisador na formação da rede, facilitando o processo de agregação das empresas, formulação de regras e regulamentações. Neste contexto, os entrevistados acreditam que o governo tem contribuído por meio das agências governamentais que apoiam o projeto, especialmente a APEX Brasil, como destaca a gerente da Casa Valduga:

“[...] a APEX tem sido a grande apoiadora. Eles estão apoiando muito o vinho brasileiro, estão apostando nesse setor, sabem que ele vai crescer e estamos conseguindo cada vez mais recursos através deles para viabilizar este crescimento" [Gerente da Casa Valduga].

Além da APEX, destaca-se o auxílio do SEBRAE, com consultorias para as empresas que participam do projeto, do Itamaraty, com a colocação de vinhos brasileiros nas embaixadas brasileiras, e do governo do estado do Rio Grande do Sul, por meio da Secretaria de Desenvolvimento e Assuntos Internacionais - SEDAI, em algumas ações específicas.

O gerente do IBRAVIN argumenta que desde o início do projeto, a entidade contou com o apoio da APEX Brasil, SEBRAE e FIERGS. O entrevistado destaca que sem o apoio da APEX o projeto ficaria inviável, haja vista que desenvolver o mercado externo é um trabalho de longo prazo e as empresas participantes do projeto dificilmente conseguiriam investir em feiras e eventos no exterior, uma vez que estes custos reduziriam a competitividade dos vinhos nacionais tanto no mercado externo como no mercado interno.

No entanto, os entrevistados destacam a existência de uma dicotomia no auxílio governamental: enquanto auxilia por meio dos subsídios ao projeto, favorecendo as exportações, não propicia suporte para as operações no mercado interno. A diretora da Vallontano diz que:

\footnotetext{
"A nossa rede tem incentivos do governo, entretanto, tem que avaliar também o mercado interno que está mal, não é reconhecido e está em último na lista de prioridades do governo" [Diretora da Vallontano].
}

A visão é compartilhada pela enóloga da Dal Pizzol. Para a entrevistada, o principal apoiador é o órgão governamental (APEX Brasil), demonstrando que acredita 
no potencial do vinho brasileiro. Por outro lado, o governo poderia auxiliar mais a cadeia do vinho e passar a enxergá-la como algo representativo. A enóloga entende que esta falta de atenção deriva da força de outros setores na área de bebidas, como no caso das cervejarias que acabam tendo mais representação junto ao governo em virtude do tamanho.

Em termos de políticas governamentais, o governo possui um papel fundamental para a manutenção da rede por intermédio do auxílio financeiro da APEX Brasil. Por outro lado, os entrevistados exaltam a falta de apoio governamental para preservar o setor no mercado interno. No entanto, focando na rede em análise, as políticas governamentais por meio dos órgãos de apoio têm gerado efeitos positivos, tanto em termos das atividades externas como no desenvolvimento da qualidade do vinho brasileiro, como por exemplo, o trabalho da Embrapa Uva e Vinho.

As relações existentes entre os atores e as políticas governamentais resultam na força motriz da rede em análise. A partir deste contexto, surgem os efeitos da participação na rede no processo de internacionalização das empresas estudadas.

\subsection{Efeitos da participação na rede}

No âmbito da rede em análise, os entrevistados ressaltam que a rede afeta de várias formas o processo de internacionalização. De maneira genérica, o enólogo da Sulvin observa que a participação na rede abre os horizontes da empresa, e desde o ingresso na rede, a empresa tem buscado ampliar os mercados e desenvolver novos produtos para atender estes mercados.

A melhoria da operação vinícola como um todo é observada pelo gerente do IBRAVIN. Para o entrevistado, a formação da rede tem ido além da promoção do vinho brasileiro no exterior, colaborando no processo de adequação das empresas para o mercado externo, e se envolvendo em atividades básicas também. Ele ressalta que depois que algumas empresas entram no projeto, incorporam uma perspectiva internacional, pois passam a ter contato com empresas que já desenvolvem atividades internacionais participantes da rede e com os importadores.

A diretora da Vallontano acredita que participando da rede, mesmo que não desenvolva nenhuma atividade no exterior, o fato de estar participando das reuniões do grupo, ouvindo, analisando as informações recebidas, minimiza a possibilidade de a empresa cometer erros estratégicos. 
Redes de promoção internacional e suas contribuições no processo de internacionalização: o caso do psi wines from brazil

Em termos específicos, a minimização dos erros destacada pela entrevistada é explicada pela literatura em função de que a participação em rede reduz a complexidade e as incertezas das operações (CHETTY; WILSON, 2003; SEPPO, 2007). Na rede em análise, esta minimização das incertezas é proporcionada por trocas informações e treinamentos ofertados.

Para o gerente do IBRAVIN, a rede contribui para diminuir os riscos e a complexidade das operações, principalmente pelos treinamentos que são oferecidos, nos quais os associados discutem questões como contratos, legislações e oportunidades no mercado externo. Nesta mesma linha, o gerente da Miolo ressalta que exportar para um mercado desconhecido é quase impossível em virtude do risco, então as informações compartilhadas pela rede facilitam o processo de ingresso num novo mercado e minimizam o risco da operação.

Para a gerente da Luiz Argenta, as informações fornecidas pelo projeto, como precauções legais e de contratos, diminui os riscos das atividades internacionais, geralmente mais complexas que as operações no mercado doméstico. Desta forma, entende-se que a rede contribui na redução dos custos de transação das operações internacionais.

Contudo, como o projeto não se envolve com a comercialização, as trocas de informações entre as empresas e a gerência do projeto previnem negócios mal sucedidos, mas não os eliminam. O diretor da Don Laurindo fala que:

“[...] a rede não diminui o risco na parte operacional, em termos de negócios e de dinheiro, visto que não se envolve em nada disso, o trabalho da rede é te colocar em eventos, em feiras, com custo baixo, fazendo apresentações no mundo" [Diretor da Don Laurindo].

Em termos financeiros, a rede contribui na redução dos custos das ações de promoção internacional. O enólogo da Sulvin destaca que sem o subsídio financeiro para a participação de eventos internacionais, ficaria inviável para as empresas menores da rede, participarem de uma feira no exterior. O gerente do IBRAVIN destaca as ações coletivas para a elaboração de material publicitário e as publicações em revistas especializadas, contribuindo com a redução de custos para as empresas.

A participação em feiras internacionais coloca as empresas frente às novidades do mercado, não só em termos de comercialização, mas também em termos de maquinários, novos modos de produção e plantio da uva, entre outros quesitos que 
podem resultar numa redução de custos. Contudo, os entrevistados observam que a participação na rede não afeta no custo do produto em si, visto que cada empresa trabalha com seus próprios produtos e, consequentemente, com os seus próprios custos.

Contudo, os entrevistados observam que o propósito da rede é a promoção comercial internacional, e não o aumento do poder de barganha junto a fornecedores como, por exemplo, o que é proporcionado pelas redes de compra. Desta forma, o efeito desejado pelos participantes, além do subsídio financeiro para a promoção internacional, centra-se na troca de informações e geração de conhecimento. Este entendimento está alinhado teoricamente com o modelo de Johanson e Vahlen (1977), para quem a geração de conhecimento e aprendizagem são fatores determinantes do processo de internacionalização.

Contudo, a formação de redes para internacionalização não está livre de efeitos negativos. $O$ gerente do IBRAVIN cita que quando algumas empresas se internacionalizam, deslumbram-se com a primeira venda para o mercado externo e não se preparam para dar continuidade neste processo:

\footnotetext{
“[...] quando incentivamos a primeira venda, um dos nossos compromissos é preparar a empresa, tanto para as coisas boas, quanto para as ruins, já que a chuva de informações muitas vezes assusta [Gerente do IBRAVIN].
}

Outro elemento destacado pelos entrevistados refere-se ao foco limitado na promoção de vinhos finos. Isto ocorre pelo fato de que algumas empresas, especialmente as localizadas em Flores da Cunha, possuem como principais produtos os vinhos de mesa (variedade de uva americana), limitando as opções de produtos ofertados nos eventos promovidos pela rede.

Os entrevistados alertam para a necessidade de uma atuação ética por parte das empresas, visto que, caso alguma vinícola participante da rede atue de maneira irresponsável, pode prejudicar as operações das demais, manchando a bandeira do grupo. Desta forma, para alguns entrevistados, a seleção e o nivelamento das empresas é importante para o sucesso da rede. Ainda nesta linha, alguns entrevistados destacam a importância de um tratamento homogêneo por parte da gerência da rede, não devendo haver privilégios com as empresas que possuem um histórico exportador mais significativo.

Em termos da difusão das informações, os entrevistados não enxergam a existência de assimetrias de informação, e sim o fato de que algumas empresas buscam mais informações junto ao projeto, podendo desta forma gerar um desequilíbrio no 
Redes de promoção internacional e suas contribuições no processo de

compartilhamento das informações. Visualiza-se que algumas empresas, especialmente as maiores, por terem uma estrutura destinada a desenvolver as exportações, conseguem usufruir melhor das informações dispostas pela rede. Contudo, estas informações estão disponíveis para todas as empresas da rede de maneira simétrica.

Em termos de autonomia na comercialização dos produtos, os entrevistados concordam que não existe perda, visto que na atual configuração do projeto a rede não se envolve na comercialização dos produtos. Assim, cada empresa tem autonomia para tomar suas próprias decisões comerciais, contando com o suporte promocional e técnico da rede.

Como observado na rede em estudo, o processo de internacionalização associado em rede gera efeitos diversos nas empresas associadas. Ressalta-se que quando as empresas integram uma rede interorganizacional formal para se internacionalizar, as estratégias coletivas influenciam a formulação das estratégias de cada empresa. Desta forma, a internacionalização de maneira associada resulta em mudanças tanto na organização como no setor em que está inserida.

\subsection{Geração de mudanças}

No que tange a geração de mudanças, os treinamentos oferecidos pela rede têm contribuído para estimular as mudanças necessárias nas empresas para viabilizar as exportações. O gerente da Miolo destaca a importância da existência de uma estrutura adequada, pelo fato de que o vinho exige cuidados especiais na exportação, como regulamentações junto a órgãos como o Ministério da Agricultura, emissões de certificados especiais, além de ser um produto que tem suas propriedades alteradas com mudanças de temperatura e umidade, exigindo uma logística internacional específica. Neste sentido, a gerente do projeto destaca a parceria com o SEBRAE que visa proporcionar um suporte técnico para que as empresas possam realizar alterações na sua estrutura visando o processo de internacionalização.

Além do suporte técnico, o acesso a informações e novos conhecimentos proporcionados pela rede são incorporados no dia-a-dia das empresas. O enólogo da Sulvin descreve uma situação em que isso ocorre:

"o projeto é importante porque você começa a buscar informações através de pessoas e contatos, e assim você muda os modos de comercialização. As 
informações do mercado influenciam a compra das uvas e através disso você vai buscar os pilares para o vinho, adaptar os processos" [Enólogo da Sulvin].

O entrevistado ainda ressalta que anteriormente à criação da rede, poucas grandes empresas do setor vinícola atuavam internacionalmente, mas, com a criação da rede, empresas menores tiveram a oportunidade de ingressar no mercado externo. A gerente da rede comenta que quando os empresários participam de uma feira, eles visualizam novidades que vão beneficiar as operações tanto no mercado externo como no mercado interno.

Visualiza-se, assim, que a rede possui papel significativo não só no processo de internacionalização das empresas associadas ao Wines from Brazil, mas também no setor como um todo. As relações entre os atores deram-se de maneira tardia em relação ao setor vinícola mundial, situação derivada principalmente do acirramento da competição no mercado interno provocado pela entrada de produtos importados.

Contudo, a união de diversos atores em torno da rede e a busca por mercados internacionais têm motivado alterações em todo o setor, visto que o desenvolvimento de produtos adequados para o mercado externo exige ações conjuntas desde o plantio da uva até a comercialização. Assim, a melhora da qualidade e da reputação do vinho brasileiro necessária para a internacionalização beneficia o setor como um todo.

\section{CONSIDERAÇÕES FINAIS}

Analisando o caso da rede Wines From Brazil, observa-se que as dificuldades do setor no mercado interno estimularam a busca de novos mercados e, consequentemente, o espírito de cooperação para superar as adversidades desta busca. A formação da rede foi a alternativa encontrada pelas empresas e entidades do setor para desenvolver a imagem do vinho brasileiro no exterior, bem como contar com o auxílio governamental para as ações promocionais.

Observa-se, assim, que as políticas governamentais de apoio às exportações, com destaque para a APEX Brasil, contribuem de maneira significativa para a internacionalização em rede. Sem este apoio, a formação da rede estaria comprometida, visto que o subsídio na participação dos eventos consiste no principal benefício obtido pelas empresas com a rede. Em consequência desta associação em rede, houve a possibilidade de troca de recursos necessários para as atividades internacionais. 
Redes de promoção internacional e suas contribuições no processo de internacionalização: o caso do psi wines from brazil

Os efeitos positivos gerados a partir da participação da rede centram-se no aprendizado e geração de conhecimentos, frutos das informações obtidas por intermédio da rede, bem como redução dos custos, complexidades e incertezas das operações internacionais. Por outro lado, os riscos ligados à operação internacional são apontados como os principais efeitos negativos.

Por fim, constatou-se que o processo de internacionalização em rede resulta em mudanças internas nas organizações participantes, especialmente em termos de adequação da estrutura administrativa para atuar internacionalmente e adoção de novas tecnologias. Além disso, as mudanças necessárias para a internacionalização beneficiam o setor como um todo. A Tabela 03 apresenta uma síntese dos resultados obtidos:

Tabela 03 - Síntese dos construtos no processo de internacionalização da Rede

\begin{tabular}{|c|c|}
\hline Construtos & Resultados Encontrado \\
\hline $\begin{array}{c}\text { Relação entre os } \\
\text { atores }\end{array}$ & 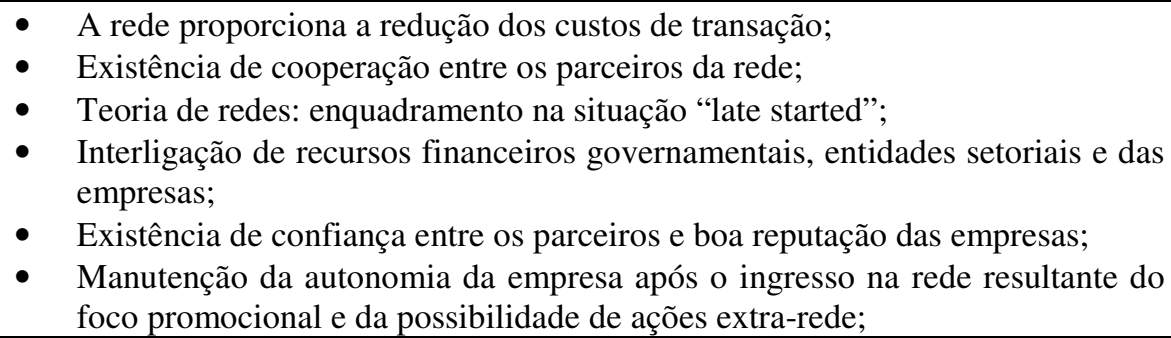 \\
\hline $\begin{array}{c}\text { Políticas } \\
\text { governamentais }\end{array}$ & $\begin{array}{l}\text { - Dicotomia nas políticas governamentais (o auxílio governamental é vital para } \\
\text { a existência da rede, contudo não há apoio para o mercado interno); } \\
\text { - Subsídio da APEX é o elemento viabilizador do projeto; } \\
\text { - Apoio de outros órgãos governamentais, como o Itamaraty e de entidades de } \\
\text { classe e associações favorecem o desenvolvimento da rede. }\end{array}$ \\
\hline $\begin{array}{l}\text { Efeitos da } \\
\text { participação na } \\
\text { rede }\end{array}$ & $\begin{array}{l}\text { - Efeitos positivos como: } \\
\text { - Desenvolvimento de uma visão internacional nas empresas; } \\
\text { - Melhora no posicionamento estratégico das empresas; } \\
\text { - Ampliação da rede de contatos; } \\
\text { - Redução da complexidade e das incertezas das operações; } \\
\text { - Redução dos riscos com destaque para os treinamentos e palestras; } \\
\text { - Troca de experiências e novas técnicas de operação entre as empresas; } \\
\text { - Redução de custos operacionais em função da redução dos custos de promoção } \\
\text { internacional e sinergias operacionais } \\
\text { - Geração de conhecimentos e aprendizagem; } \\
\text { - Troca de informações entre as empresas e a gerência da rede; } \\
\text { - Maior representatividade e competitividade das empresas no setor nacional e } \\
\text { internacional vinícola; } \\
\text { - Difusão de inovações entre as empresas participantes; } \\
\text { - Efeitos negativos como: } \\
\text { - Manutenção dos riscos na operação (comercialização, embarque, financeiro); } \\
\text { - Geração de expectativas em acesso em função do ingresso na rede; } \\
\text { - Limitação da linha de produtos foco do projeto; } \\
\text { - Risco de atuação aética e descompromissada com a rede; } \\
\text { - Assimetrias quanto à absorção dos benefícios proporcionados pela rede. }\end{array}$ \\
\hline $\begin{array}{l}\text { Geração de } \\
\text { mudanças }\end{array}$ & $\begin{array}{l}\text { - Geração de mudanças internas nas empresas com a adequação da estrutura } \\
\text { administrativa e adoção de inovações; } \\
\text { - Geração de mudanças no setor como um todo com o aumento da } \\
\text { competitividade do vinho brasileiro. }\end{array}$ \\
\hline
\end{tabular}


Diante destas considerações, pode se concluir que a formação da rede contribui no processo de internacionalização das empresas associadas, tanto por meio do suporte financeiro nas ações promocionais internacionais, como na troca de informações e conhecimentos proporcionada pelos envolvidos na rede. A rede também demonstrou tratar-se de uma estrutura de ligação entre empresas, governo e entidades setoriais, num processo sinérgico de desenvolvimento de mercados externos e adequação ao cenário internacional.

Estes achados reforçam a importância da troca de recursos entre diferentes atores no processo de internacionalização do setor vinícola brasileiro. Dado o estágio de desenvolvimento internacional deste setor em relação a competidores internacionais, o suporte de entidades setoriais e de órgãos governamentais tem um papel chave no estimulo às atividades internacionais. As relações entre os atores e o suporte governamental atuam de forma agregativa no processo de internacionalização das empresas associadas à rede, promovendo efeitos que atingem tanto as empresas participantes como o setor em que a rede atua. Estes resultados, ao mesmo tempo em que reforçam estudos anteriores, colaboram com o avanço teórico no âmbito da teoria de redes e internacionalização, pois promovem um entendimento amplo do papel de uma rede formal e suas contribuições no processo de internacionalização das empresas e do setor.

Em termos gerenciais, estes resultados contribuem com um melhor entendimento dos efeitos proporcionados pela formação de redes para a internacionalização, tanto em termos positivos quanto negativos. A associação em redes consiste numa opção estratégica, especialmente no caso de setores menos desenvolvidos internacionalmente e de pequenas e médias empresas, como no caso do setor vinícola brasileiro. A inserção na rede proporciona recursos valorosos para internacionalização, que individualmente seriam difíceis de obter, consistindo, assim, numa ferramenta de auxílio para superar barreiras à internacionalização.

Em adição, os resultados contribuem na tangente da formulação de políticas públicas de estímulo à formação de redes de promoção internacional. No caso da rede em análise, o subsídio governamental é um elemento chave na formação da rede. Diante deste entendimento, elaboradores de políticas de estímulo a exportações podem considerar a formação de redes como um mecanismo útil para fomentar a competitividade internacional das empresas.

Este estudo apresentou um foco na percepção dos gerentes da rede e das empresas participantes. Desta forma, as consequências da rede estão limitadas à 
percepção destes. Neste sentido, são estimuladas análises futuras com foco no desempenho internacional das empresas, visando ampliar os resultados obtidos. A análise de redes para a internacionalização, ao passo que contribui no entendimento da formulação de estratégias coletivas com foco internacional, oferece subsídios para formulação de políticas públicas que incentivem a internacionalização do setor.

\section{REFERÊNCIAS}

ASSENS, C.; BOUCHIKHI, H. La dialectique de la coopération et de la compétition dans um réseau d'entreprises. In. VII Conférence de l'Association Internationale de Management Stratégique, VII, Les Côtes de Carthage, 1999. Anais... Les Côtes de Carthage: AIMS, 1999.

BARDIN, L. Análise de conteúdo. Lisboa: Edições 70, 1977.

BARNEY, J. Firm resources and sustained competitive advantage. Journal of management. v. 17, n. 1, p. 99-120, 1991.

BELSO-MARTINEZ, J. Why are some Spanish manufacturing firms internationalizing rapidly? The role of business and institutional international networks.

Entrepreneurship \& Regional Development. v. 18, n. 5, p. 207-226, 2006.

BRITO, C. M. Issue-based nets: a methodological approach to the sampling issue in industrial networks research. Qualitative Market Research: an international journal. v. 2, n. 2, p. 92-102, 1999.

Estratégias de internacionalização e cooperação empresarial. Faculdade de Economia do Porto, Working paper $\mathbf{n}^{\mathbf{0}}$ 38. Disponível em $<$ www.fep.up.pt/docentes/cbrito/Estrat_Intern_e_Coop.pdf $>$ Acessado em: julho de 2007.

BUCKLEY, P. This limits of explanation: testing the internalization theory of the multinational enterprise. Journal of International Business Studies. v. 19, n. 2, p.181193, 1988.

CASTELLS, M. A sociedade em rede. São Paulo: Paz e Terra, 1999.

CAVUSGIL, S. T. Guidelines for export market research. Business Horizon. n. 28, v. 6, p. 27-33, 1985. 
CHEN, H.; CHEN, T-J. Network linkages and location choice in foreign direct investment. Journal of International Business Studies. v. 29, n. 3, p. 445-467, 1998.

CHESNAIS, F. A mundialização do capital. Rio de Janeiro: Xamã, 1996.

CHETTY, C.; HOLM, D.B. Internationalization of small to medium sized manufacturing firms: a network approach. International Business Review. v. 9, p. 7793, 2000.

CHETTY, S.; AGNDAL, H. Role of inter-organizational networks and interpersonal networks in an industrial district. Regional Studies. v. 42, n. 2, p. 175-187, 2008.

CHETTY, S.K.; WILSON, H.I.M. Collaborating with competitors to acquire resources. International Business Review. v. 12, n. 1, p. 61-81, 2003.

COVIELLO, N.B.; MUNRO, H.J. Growing the entrepreneurial firm: networking for international market development. European Journal of Marketing. v. 29, n. 7, p. 4961, 1995.

CYERT, R.M.; MARCH, J. G. A behavioral theory of the firm. Englewood Cliffs, N.Y.: Prentice Hall, 1963.

DUNNING, J. The eclectic paradigm of international production: a restatement and some possible extensions. Journal of International Business Studies. n. 19, v. 1, p. 1$31,1988$.

DYER, J.H.; SINGH, H. The relational view: cooperative strategy and sources of interorganizational competitive advantage. Academy of Management Review. 23. n. 4, p. 660-679, 1998.

EASTON, G. Industrial networks: a review. In. AXELSSON, B.; EASTON, G. (eds.) Industrial networks: a new view of reality. London: Routledge, 1992.

EBERS, M.; JARILLO, J.C. The construction, forms and consequences of industry networks. International Studies of Management \& Organization. v. 27, n. 4. p.3-21, 1997.

ECHEVERRI-CARROLL, E.L.; HUNNICUTT, L.; HANSEN, N. Do asymmetric networks help or hinder small firms' ability to export? Regional Studies. v. 32, n. 8, p. 721-733, 1998. 

internacionalização: o caso do psi wines from brazil

ELANGO, B.; PATTNAIK, C. Building capabilities for international operations through networks: a study of Indian firms. Journal of International Business Studies. v. 38, n. 4, p. 541-555, 2007.

ELO, M. SME internationalization from a network perspective: empirical study on a Finnish-Greek business network. Abo: Abo Akademi University Press, 2005.

FENSTERSEIFER, J. E. The emerging Brazilian wine industry: challenges and prospects for the Serra Gaúcha wine cluster. International Journal of Wine Business Research. v. 19, n. 3, p. 187-206, 2007.

FLEURY, A.; FLEURY, M. T. Competitive strategies and core competencies: perspective for the internationalization of industry in Brazil. Integrated Manufacturing Systems. v. 14, n. 1, p. 16-25, 2003.

GARCIA-PARPET, M. F. Mundialização dos mercados e padrões de produção: vinho, o modelo francês em questão. Tempo Social. v. 16, n. 2, p. 129 -150, 2004.

GLASER, B. G.; STRAUSS, A. L. The discovery of grounded theory: strategies for qualitative research. New York: Aldine, 1967.

GRANOVETTER, M. The strength of weak ties. American Journal of Sociology. v. 78, n. 6, p. 1360-1380, 1973.

HÅKANSSON, H.; JOHANSON, J. A model of of industrial networks. In. AXELSSON, B.; EASTON, G. (eds.). Industrial networks: a new view of reality. London: Routledge, 1992.

JOHANSON, J.; VAHLNE, J-E. The internationalization process of the firm: a model of knowledge development and increasing foreign market commitments. Journal of International Business Studies. v. 8, n.1, p.23-32, 1977.

JOHANSON, J.; MATTSSON, L. Internationalization in industrial systems: a network approach. In. HOOD, N.; VAHLNE, J. (eds.). Strategies in global competition. New York: Croom Helm, 1988.

JOHANSON, J.; WIEDERSHEIM-PAUL, F. The internationalization of the firm: four Swedish cases. Journal of Management Studies. v. 12, n. 3, p.305-322, 1975. 
JOHANSON, J.; VAHLNE, J. The Uppsala internationalization process model revisited: from liability of foreignness to liability of outsidership. Journal of International Business Studies. v. 40, n. 1, p. 1411-31, 2009.

LAM W. L.; WHITE, P. L. An adaptive choice model of the internationalization processes. The International Journal of Organizational Analysis. v. 7, n. 2, p.10534, 1999.

LOANE, S.; BELL, J. Rapid internationalisation among entrepreneurial firms in Australia, Canada, Ireland and New Zealand - an extension to the network approach. International Marketing Review. v. 23, n. 5, p. 467-485, 2006.

MARCON, M.; MOINET, N. La stratégie-réseau. Paris: Éditions Zéro Heure, 2000.

MILES, R.; SNOW, C. C. Network organizations: new concepts for new forms. California management review. v. 23, n. 3, p. 62 - 73, 1986.

NEERGAARD, H. Networks as vehicles of internationalization: network relationships and the internationalization process of small furniture manufacturers. PhD thesis.

Department of International Business, The Aarhus School of Business, Aarhus, 1999.

PARKHE, A.; WASSERMAN S.; RALSTON, D.A. New frontiers in network theory development. The Academy of Management Journal. v. 31, n. 3, p. 560-568, 2006.

PEDERSEN, K. The eclectic paradigm: 25 years anniversary. In. International Business and Economy Conference, I, San Francisco, 2002. Anais... San Francisco: IBEC, 2002.

PENROSE, E. The theory of the growth of the firm. Basil Blackwell: Oxford, 1966.

PERRY, M. Small firms and network economies. London: Routledge, 1998.

POWEL, W.W. Hybrid organizational arrangements: new form or transitional development? Californian Management Review. v. 30, n. 1, p. 67-86, 1987.

RING, P. S.; VAN DE VEN, A. Structuring cooperative relationships between organizations. Strategic Management Review. v. 13, n. 7, p. 483-498, 1992.

ROOLAHT, T. The company's involvement in international networks as an entrepreneurial decision. Baltic Management Review. v. 1, n.1, p.102-15, 2006. 
SADLER, A.; CHETTY, S. The impact of networks on New Zealand firms. Journal of Euromarketing. v. 9, n. 2, p. 37- 58, 2000.

SAKAKIBARA, M.; DODGSON, M. Strategic research partnerships: empirical evidence from Asia. Technology Analysis and Strategic Management. v. 15, n. 2, p. 228-245, 2003.

SEPPO, M. The role of business networks in the internationalization of Estonian chemical industry enterprises. Tartu: Tartu University Press, 2007.

WELCH, D.E.; WELCH, L.S.; YOUNG, L.C.; WILKINSON, I.F. The importance of networks in export promotion: policy issues. Journal of International Marketing. $v$. 6, n. 4, p. 66-82, 1998.

WILIAMSON, O. Markets and hierarchies: analysis and antitrust implications. New York: The Free Press, 1975.

WILKINSON, I.F.; MATTSSON, L.G.; EASTON, G. International competitiveness and trade promotion policy from a network perspective. Journal of World Business. v. 35 , n. 3, p. 275-99, 2000.

WILSOM, E. J.; WOODSIDE, A.G. Supplier choice strategies in industrialized nations. International Marketing Review. v. 2, n. 4, p. 75-79, 1985.

YIN, R. Estudo de caso: planejamento e métodos. 2. ed. Porto Alegre: Bookman, 2001.

YEUNG, H.W. Qualitative personal interviews in international business research: some lessons from a study of Hong Kong transnational corporations. International Business Review. v. 4, n. 3, p. 313-339, 1995. 